Published in final edited form as:

Appetite. 2013 June ; 65: 210-219. doi:10.1016/j.appet.2013.02.010.

\title{
Development of the Responsiveness to Child Feeding Cues Scale
}

\author{
Eric A. Hodges, PhD, FNP-BC ${ }^{1}$, Susan L. Johnson, $\mathrm{PhD}^{2}$, Sheryl O. Hughes, $\mathrm{PhD}^{3}$, Judy M. \\ Hopkinson, $\mathrm{PhD}^{4}$, Nancy F. Butte, $\mathrm{PhD}^{3}$, and Jennifer O. Fisher, $\mathrm{PhD}^{5}$ \\ ${ }^{1}$ School of Nursing, University of North Carolina, Chapel Hill NC \\ ${ }^{2}$ Department of Pediatrics, University of Colorado - Denver, Denver CO \\ ${ }^{3}$ Department of Pediatrics, Baylor College of Medicine, USDA/ARS Children's Nutrition Research \\ Center, Houston TX \\ ${ }^{4}$ Retired \\ ${ }^{5}$ Department of Public Health, Center for Obesity Research and Education, Temple University, \\ Philadelphia, PA
}

\begin{abstract}
Parent-child feeding interactions during the first two years of life are thought to shape child appetite and obesity risk, but remain poorly studied. This research was designed to develop and assess the Responsiveness to Child Feeding Cues Scale (RCFCS), an observational measure of caregiver responsiveness to child feeding cues relevant to obesity. General responsiveness during feeding as well as maternal responsiveness to child hunger and fullness were rated during midmorning feeding occasions by 3 trained coders using digitally-recordings. Initial inter-rater reliability and criterion validity were evaluated in a sample of 144 ethnically-diverse mothers of healthy 7- to 24-month-old children. Maternal self-report of demographics and measurements of maternal/child anthropometrics were obtained. Inter-rater agreement for most variables was excellent (ICC >0.80). Mothers tended to be more responsive to child hunger than fullness cues $(\mathrm{p}<0.001)$. Feeding responsiveness dimensions were associated with demographics, including maternal education, maternal body mass index, and child age, and aspects of feeding, including breastfeeding duration, and self-feeding. The RCFCS is a reliable observational measure of responsive feeding for children $<2$ years of age that is relevant to obesity in early development.
\end{abstract}

\section{Keywords}

Responsive feeding; Feeding cues; Hunger and fullness; Child appetite

(C) 2013 Elsevier Ltd. All rights reserved.

Correspondence concerning this article should be addressed to Jennifer Orlet Fisher, PhD, Center for Obesity Research and Education, 3223 N. Broad Street, Suite 175, Philadelphia, PA 19140. jofisher@temple.ed.

Publisher's Disclaimer: This is a PDF file of an unedited manuscript that has been accepted for publication. As a service to our customers we are providing this early version of the manuscript. The manuscript will undergo copyediting, typesetting, and review of the resulting proof before it is published in its final citable form. Please note that during the production process errors may be discovered which could affect the content, and all legal disclaimers that apply to the journal pertain. 


\section{Introduction}

Obesity is a pressing threat to both US adults and children, where increasing numbers of the youngest segment of the population are being affected. Nationally representative data indicate that in $2009-2010,9.7 \%$ of children aged 0 to 2 years were obese ( $\geq 95^{\text {th }} \%$ weightfor-length), with Hispanics having the highest percentage at $14.8 \%$ and non-Hispanic Whites having the lowest at $8.4 \%$ (Ogden, Carroll, Kit, \& Flegal, 2012). Many obese infants will not "grow out of it". Heavy infants and those who show rapid weight gain are at increased risk for obesity in later periods of development (Brisbois, Farmer, \& McCargar, 2012). For example, in a retrospective study of 184 older overweight children ( $285^{\text {th }} \% \mathrm{BMI}$ ), the median age of overweight onset was 15 months, with $25 \%$ overweight by 3 months (Harrington et al., 2010). Thus, the first two years of life are increasingly recognized as an important target for prevention efforts (Committee on Obesity Prevention Policies for Young Children, 2011; Paul et al., 2009).

The first few years of life involve major transitions in children's eating skills as they move from complete dependence on the caregiver during infancy to relatively autonomous eating by toddlerhood. Throughout this time, however, children are dependent on their caregivers for adequate and appropriate nutrition. Caregiver feeding patterns that are unresponsive to infant hunger and/or fullness cues are thought to contribute to over-nutrition by promoting eating in the absence of hunger and/or eating beyond fullness, respectively (Bruch, 1981; Costanzo \& Woody, 1985; DiSantis, Hodges, Johnson, \& Fisher, 2011; Hurley, Cross, \& Hughes, 2011; Wright, 1981; Wright, 1987). Alternatively, child-centered feeding approaches that are responsive to a child's hunger and fullness cues are thought to support developing control of appetite, and specifically the ability to attend to internal biologicallydriven cues or sensations when eating (DiSantis et al., 2011; Hurley et al., 2011). This view of parental responsiveness to child feeding draws on broader developmental definitions of parental responsiveness and sensitivity (Ainsworth \& Bell, 1969; Ainsworth, Bell, \& Stayton, 1974; Bornstein, 1989; Lamb \& Easterbrooks, 1981), and has three components: 1) perception of the child's cue, 2) accurate interpretation of the cue, and 3) appropriate response to the cue. Responsiveness to child feeding cues is also part of a broader definition of responsive feeding which considers the structure, routine, and emotional context provided by the caregiver (Black \& Aboud, 2011; Engle, Bentley, \& Pelto, 2000).

To date, much of the work linking responsive parenting to child obesity has been conducted with preschool aged children and has relied on parental self-reports of child feeding styles and practices (Birch et al., 2001; Hughes, Power, Orlet Fisher, Mueller, \& Nicklas, 2005; Musher-Eizenman \& Holub, 2007; Wardle, Sanderson, Guthrie, Rapoport, \& Plomin, 2002). In general, unresponsive feeding practices appear to have counterproductive effects on dimensions of eating behavior (Ventura \& Birch, 2008) and have been modestly associated with obesity among preschool aged children in middle-to-high income countries (Hurley et al., 2011). Responsiveness to feeding cues is implicit in this body of research as well as in a more limited number of studies of children under two years of age. For example, higher level of maternal control during feeding, when assessed through self-report (Brown \& Lee, 2011a), has been positively associated with infant weight gain. The same relationship has been found when assessing maternal control during feeding through observation ( Farrow \& 
Blissett, 2006), but only for those infants with high weight gain in the first 6 months of life. However, maternal pressure to eat and restriction at 1 year predicted lower weight at 2 years when controlling for 1 year weight ( Farrow \& Blissett, 2008). In other work, baby-led weaning, in which infants are allowed to self-feed complementary foods from the outset of their introduction, as opposed to being spoon fed by a caregiver, has been associated with lower maternal control during feeding (Brown \& Lee, 2011b) and, alternatively, greater food acceptance and lower weight (Townsend \& Pitchford, 2012). The findings of these studies are certainly consistent with those in older children and suggest a role of responsive feeding in infant over nutrition. However, to date, few studies have explicitly assessed child feeding cues and the responsiveness of feeding initiation and termination to those cues, particularly in the first two years of life (Agras et al., 2012; DiSantis et al., 2011).

This paper reports the development and initial psychometric evaluation of an observational measure of caregiver responsiveness to child hunger and fullness cues during the first two years of life. An observational approach was taken because caregiver self-reports of feeding behavior have been found to differ from observed feeding behaviors (Lewis \& Worobey, 2011; Sacco, Bentley, Carby-Shields, Borja, \& Goldman, 2007), and the latter are thought to capture behaviors that may not be reported or considered salient in self-reports of feeding interactions, but that may nonetheless have an important influence on children's eating development. There are a number of existing observational measures of feeding interactions in early development, including the Nurse Child Assessment Feeding Scale (NCAFS; (Sumner \& Spietz, 1994), the Feeding Scale (Chatoor et al., 1997), and the Parent Child Early Relational Assessment (PCERA;(Clark, 1999)), and the Feeding Interaction Scale (FIS;(Wolke, Sumner, McDermott, \& Skuse, 1987)). These measures have primarily been used clinically to evaluate eating pathology in the case of growth faltering (The Feeding Scale, FIS) or to study broader interaction quality (NCAFS, PCERA, FIS) rather than to examine specific feeding behaviors and interactions around child hunger and fullness cues. In addition, the use of the NCAFS and PCERA is limited to the first year of life. Thus, the aim of this research was to develop the Responsiveness to Child Feeding Cues Scale (RCFCS), an observational measure of dyadic feeding interactions with relevance for developing controls of appetite and obesity for caregivers of children under two years of age. A provisional coding scheme of the RCFCS was piloted and refined. A study of ethnically-diverse mothers of healthy infants and toddlers was conducted to evaluate interrater agreement and preliminary criterion validity associations of the RCFCS with child anthropometric and family demographics.

\section{Methods}

\section{Participants}

Participants in the main development study were ethnically diverse mothers and their healthy 7- to 24-month-old children who were taking part in a larger study of dietary assessment methods in Houston, TX (Fisher et al., 2008). Reflecting the design of the larger study, recruitment was blocked on maternal ethnicity/race and child age to provide roughly equal numbers of mothers who self-identified as non-Hispanic White, non-Hispanic Black, and Hispanic, and who reported primary feeding responsibility for an infant (7-11 months) 
or a toddler (12-24 months). Other child inclusion criteria included term birth (37-42 weeks) and weight-for-age of $>5^{\text {th }}$ percentile at birth (Kuczmarski et al., 2000). Child exclusion criteria for the main study were feeding problems and chronic medical conditions or medication use. Additionally, to minimize social desirability, mothers who reported having a degree in nutrition and/or psychology were excluded from the feeding observation.

Convenience sampling was employed to recruit mothers from the greater metropolitan Houston area using a volunteer database, flyers, and on-site recruiting at childcare classes, city-wide festivals and expositions attracting families, doctors' offices, retail stores, and churches. One child was surveyed per household. Mothers provided consent for their own and their child's participation. All procedures were approved by and executed according to the standards of the Baylor College of Medicine Institutional Review Board.

\section{Procedures}

Data were collected at the USDA/ARS Children's Nutrition Research Center, Houston, TX. Feeding sessions were recorded for two hours during a mid-morning feed. Mothers were instructed to abstain from feeding the child immediately before the observation. Mothers were then instructed to feed as little or often as desired during the observation and asked to feed their child using a highchair in the room or seated in a comfortable chair if breast- or bottle-feeding. Observations were made in a private, observation room on the Metabolic Research Unit floor of the Center. The room housed a high chair, rocker, crib, changing table, TV/VCR, and private bathroom. Feeding sessions were digitally recorded using two pan-tilt-zoom cameras (Kalatel Cyberdome 400 Series, General Electric Interlogix) that were ceiling-mounted to capture different angles; standard filming protocols were established based on these views.

Feeds were defined as involving the ingestion of solids or liquids, including water. Feeds eligible for coding were those in which mother and child were filmed without obstruction for 10 minutes prior to the feed until 1 minute after the last food to mouth contact or the child/food was moved from the feeding location-whichever came first. Feeds that occurred within 2 minutes of one another were considered part of the same feed.

\section{Measures}

Demographics-Demographic information obtained included household income, marital status, maternal education, maternal employment and breastfeeding status.

Maternal and Child Anthropometrics-Child length and weight were measured by trained research nurses. Electronic scales (Sartorius 3862 MP 6, Goettingen, Germany) were used to measure weight to the nearest $0.1 \mathrm{~g}$, and infant length boards (Holtain Limited, Crymych, Dyfed, Britain) were used to measure length to the nearest $0.1 \mathrm{~cm}$. CDC 2000 growth charts were used to calculate head circumference-for-age, weight-for-age, length-forage, and weight-for-length z-scores (Kuczmarski et al., 2000). Maternal height (Harpenden Stadiometer, Holtain Limited, Crymych, Dyfed, Britian) and weight (Health-o-meter Doctor Scale 431/432KL series, Bridgeview, IL, USA) measurements were obtained to the nearest $0.1 \mathrm{~cm}$ and $0.1 \mathrm{~kg}$, respectively (Lohman, Roche, \& Martorell, 1988). All measurements 
were obtained in duplicate and averaged (Slaughter \& Lohman, 1976). Body mass index scores were calculated as BMI=weight $(\mathrm{kg}) /$ height $\left(\mathrm{m}^{2}\right)$.

Responsiveness to Child Feeding Cues Scale (RCFCS)—The development of the RCFCS coding scheme was shaped by multiple perspectives. A multi-disciplinary team was assembled to provide complementary theoretical and clinical perspectives on child feeding behavior. The team included a family nurse practitioner (EAH), nutritionists (JOF, SLJ, and $\mathrm{NB})$, a developmental psychologist ( $\mathrm{SOH})$, and a lactation physiologist $(\mathrm{JH})$.

\section{Development of Coding Scheme}

Theoretical Foundations-It has long been thought that responsive feeding influences child obesity risk (Bruch, 1981; Costanzo \& Woody, 1985; DiSantis et al., 2011; Hurley et al., 2011). Grounded in attachment theory, caregiver sensitivity and responsiveness during feeding is believed to support healthy psychological and physical development, including self-regulation of appetite (Ainsworth \& Bell, 1969; Bowlby, 1969; Lamb \& Easterbrooks, 1981). The RCFCS uses a transactional perspective (Sameroff \& Chandler, 1975) which posits that both caregiver and child contribute to responsive feeding interactions in a bidirectional manner. When applied to the feeding context, rather than solely reacting to the caregiver, the child is viewed as having an active role in shaping feeding transactions through feeding cues and eating behaviors reflecting biological needs as well as the disposition of the child. The responses of the caregiver to the child's cues and behaviors, in turn, are thought to modify the initiation and termination of eating in a manner that shapes the child's intake and subsequent regulation of appetite.

The RCFCS uses discrete behaviors of the mother (e.g., offering food) and child (e.g., pushing food away) to allow both microanalytic and global analyses of dyadic transactions across the course of a feeding (Bakeman \& Quera, 2011; Lindahl, 2001). The RCFCS includes feeding cues that span the period from early infancy (e.g., rooting) to toddlerhood (e.g., reaching for a cup) to allow examination of feeding responsiveness within and across the periods of early child development. For example, this allows assessments of variability in feeding behaviors and behavioral patterns among 3-month-old infants and their caregivers, while also providing opportunities for developmental comparisons between 3month-old and 6-month-old infantcaregiver dyads. A caregiver's responsiveness to hunger cues is coded separately from responsiveness to fullness cues to take into account the possibility that caregiver responsiveness to the child may vary based on the type and perceived meaning of the child's cues. For example, one dyad may show dyssynchronous interactions related to hunger whereas another may be in tune with each other during feeding initiation, but show less responsiveness during the termination of feeding. Other dyads may have some combination of obesogenic patterns. Knowledge of such patterns could direct the clinician to appropriately tailor feeding interventions.

Development of Codes and Variables-The main variables and definitions of the RCFCS are provided in Table 1. 
Hunger and Fullness Cues: Child behaviors thought to reflect hunger and fullness across the first 2 years of life were drawn from a surprisingly scant literature (e.g. (Crow, 1977; Gesell \& Ilg, 1937; Korner, Chuck, \& Dontchos, 1968; Morris, Rogers, \& Taper, 1983)), existing measures such as the NCAFS, clinical/research experiences of the inter-disciplinary team, and qualitative research conducted by the authors describing factors influencing the initiation and termination of infant feeding (Hodges, Hughes, Hopkinson, \& Fisher, 2008).

The presence or absence of 48 different types of feeding cues as well as their frequency of occurrence were coded. Twenty types of hunger cues, thought to reflect the motivation to eat (Blundell et al., 2010), were coded from the beginning of the observation until 1 minute following the first food to mouth contact. Twenty-eight types of fullness cues, thought to reflect satiation (Blundell et al., 2010), were coded from food preparation until the food or the child was removed from the feeding location-whichever occurred last. Hunger and fullness cues were categorized broadly into Early (e.g. increased alertness, sucking on hands), Active (e.g. excitatory limb movements, leaning towards foods), and Late (e.g. crying) cue categories, reflecting a temporal sequencing of increasing cue intensity (Beebe $\&$ Stern, 1977). Beebe and Stern (1977) proposed that infants communicate states and needs with subtle cues that become increasingly active and overt until a caregiving response is given. Early feeding cues were considered to be relatively subtle and primarily oral in nature (e.g. mouthing). Active feeding cues were considered to be more overt and involve more full body movements (e.g. reaching for food). Negative active feeding cues (e.g. fussing) were distinguished from other active cues. Late feeding cues were considered to be very overt and involve negative affect (e.g. crying). In addition, coders rated the Strength of Child Hunger Cues and Strength of Child Fullness cues on a 5-point Likert-type scale that ranged from Not Apparent-(1) to Exremely Strong-(5). These summary ratings were made separately for Early, Active, and Late types of hunger and fullness cues.

Caregiver Responsiveness to Feeding Cues: Global ratings of caregiver responsiveness to child hunger, child receptiveness to being fed, and fullness cues were coded on a 5-point Likert-type scale, from Highly Responsive-(5) to Highly Unresponsive-(1), using definitions informed by Ainsworth and Bell (1969) 1972) and Lamb and Easterbrooks (1981). Caregiver responsiveness was defined by the latency of caregiver's feeding response to the child's cues observed across the course of a feeding episode. Specifically, ratings were made according to the types of cues given by the child (i.e. Early, Active, and Late cues) at the point when the caregiver responded. The focus of the definition on latency permits evaluation of caregiver feeding responsiveness across developmental changes in the types of cues given (reflexive to intentional), type of food observed (e.g. milk to solid), and type of feeding (fed by mother to self-fed).

Responsiveness to Child Hunger Cues was rated based on the types of hunger cues observed from the beginning of the observation up to the time the caregiver initiated food preparation which was defined as the point at which the mother began to prepare food or the child was placed in feeding location/position — whichever came first. Maternal Responsiveness to the Child's Receptiveness to Being Fed was rated based on the relative proportion of hunger and fullness cues observed from the beginning of food preparation until 1 minute following the first food to mouth contact. Responsiveness to Fullness Cues was rated based on the types of 
fullness cues observed from 1 minute after the first food to mouth contact until 1 minute following the last food to mouth contact or the food/child was removed from the feeding location - whichever came first. Caregivers who responded to earlier and more subtle feeding cues were rated as having higher responsiveness to child feeding cues than those caregivers who responded to later and more overt child feeding cues. For instance, a mother who was observed to feed beyond early and repeated active signs of fullness would be rated as being unresponsive to fullness cues. Operational definitions for responsiveness were designed to accommodate variability in infant/child temperament by allowing that the first cues given by some children may be relatively overt (i.e. active or late).

General Responsiveness During Feeding: In attempt to characterize the general quality of dyadic interaction during feeding, general responsiveness of the caregiver and child to one another was assessed using four component constructs ( Ainsworth, 1969; Lavelli \& Poli, 1998; Mentro, Steward, \& Garvin, 2002): Visual Attentiveness, Positive Expressiveness (verbal and non-verbal, e.g., infant cooing, affectionate touch), low Negative Expressiveness (verbal and non-verbal, e.g., infant fussing/crying, hitting), and having a Relaxed Physical Disposition during feeding. Each of the component dimensions was coded separately for mother and child on a 5-point Likert-type scale ranging from Not at All- (1) to Very-(5), from the beginning of food preparation (or child placed in feeding location/position) until 1 minute after the last food to mouth contact or the child/ food was removed from the feeding location-whichever came first. General Responsiveness During Feeding was scored as the mean of Visual Attentiveness, Positive Expressiveness, Negative Expressiveness (reverse scored), and Relaxed Physical Disposition during feeding.

Contextual Variables: A number of variables were scored to describe the context in which feeding took place. The Type of Feeding Observed (breast-fed, bottle-fed, fed solids, or mixed feeding involving liquids and solids) as well as Who Fed the Child during the observation were scored. The codes for Who Fed the Child were collapsed, for the purposes of the analyses, to describe self-feeding: (1) child completely self-fed or with minimal assistance from caregiver vs. (0) caregiver completely fed child or with minimal participation from child or balanced participation.

Pilot Testing and Refinement of Provisional Coding Scheme-The provisional coding scheme was initially pilot-tested with 92 ethnically diverse mothers (51 non-Hispanic White, 17 non-Hispanic Black, 17 Hispanic, 5 other, 2 missing) of 3-month (n=29), 6 month $(n=30)$ and 12 month old $(n=33)$ infants. Roughly, one third of women were first time mothers. Infants were, on average, of healthy weight, and approximately half were female. The coding scheme was applied to a mid-morning feed between the hours of 10-12 AM selected from a longer 8 hour observational session in which the quality of the video was sufficient to view the mother and infant without obstruction. Five trained coders rated the videotapes, and inter-rater agreement was assessed on $15 \%$ of the cases, where raters were randomly assigned to code a proportion of each other's cases. Inter-rater agreement was acceptable for the four dimensions of General Responsiveness During Feeding (e.g. Visual Attentiveness, Positive Expressiveness) for child (ICC $=0.61-0.80$ ) and mother (ICC $=0.61-0.86$ ) with the exception of Relaxed Physical Disposition during feeding 
(ICC=0.48). Inter-rater agreement for Maternal Responsiveness to Child Hunger (ICC $=0.57$ ) and Fullness ( $\mathrm{ICC}=0.68$ ) cues were also fair, but acceptable. Based on these results and multiple discussions with coders it was determined that the operational definitions did not adequately capture responsive feeding interactions during self-feeding. In such cases, mothers might have been seated at greater distance from the child and were less visually attentive as well as interactive during the feeding, but otherwise responded promptly and appropriately to the child. As a result, the operational definitions of General Responsiveness During Feeding, as well as those involving responsiveness to feeding cues, were revised to more comprehensively consider the application of the definitions during self-feeding. The revised coding scheme was used in the main study.

Coder Training-The feeding observations made in the main development study were coded by three individuals who received extensive training over a period of 2 weeks prior to the commencement of coding. Definitions for all variables were reviewed and discussed by the primary authors (EAH, JOF) and coders to ensure clarity in their application. In addition, video-taped examples of behaviors were discussed as a group to build consensus in applying the definitions and provide opportunities for practice. Once the authors and the coders team felt that the RCFCS was being used as intended, the coders were required to code three goldstandard videos representing different ages and types of feeders (e.g., completely fed by the mother, assisted by the mother, completely self-fed). The gold standard videos were created by the authors (EAH, JOF) by separately coding each video and then working jointly to resolve any discrepancies in application of the coding definitions. Coders were required to code the gold standard videos to $85 \%$ agreement before they were allowed to begin coding for the study. Coding took place over a 3 month period. Coders met weekly to address and resolve questions that arose in the process of coding. Coders completed their own assignments as well as coded cases for which inter-rater agreement was assessed. The coders were asked to re-code the gold standard tapes once, mid-way through coding.

\section{Statistical Analysis}

Analyses were conducted with SPSS (Version 19, IBM Corporation, Armonk, NY) and SAS (Version 9.2, SAS Institute, Inc., Cary, NC). Inter-rater agreement was assessed for all constructs using 5-point rating scales using the absolute measure intra-class correlation coefficient (ICC) for multiple raters (Bakeman \& Quera, 2011; Shrout \& Fleiss, 1979). The following rule of thumb was used to interpret values of the absolute measure ICC: $<0.50=$ unacceptable, $0.50-0.70=$ fair, $0.70-0.80=$ good, and $\geq 0.8=$ excellent (Blacker, 2005). Unweighted Kappa (K) was used to evaluate chance-corrected agreement for variables with dichotomous ratings (Fleiss, 1971) and followed general rules of thumb for interpretation (Landis \& Koch, 1977). Pearson product-moment correlations were used to describe associations among RCFCS variables. To provide preliminary evidence of criterion validity, associations of RCFCS responsiveness variables with child and maternal characteristics were evaluated using Pearson's Rank-Order correlations and general linear models that tested mean differences in responsiveness variables across demographic groups. Child characteristics included child weight-for-length, gender, age group, type of feeding observed, and who fed the child during the observation. Maternal characteristics included body mass index, age, education, income, employment, ethnicity, number of children, and 
breastfeeding duration. The level of statistical significance deemed to be meaningful was $\mathrm{p}<0.05$. However, given the developmental nature of the work, the $\mathrm{p}$-value of associations where $\mathrm{p}<0.10$ was also noted.

\section{Results}

\section{Participant Characteristics}

Participants were 157 ethnically diverse mothers (56 non-Hispanic white, 51 non-Hispanic black, 50 Hispanic) and their 7- to 11-month-old infants $(\mathrm{N}=80)$ or 12- to 24 month-old toddlers $(\mathrm{N}=77)$. Mothers were, on average, in the early 30 's, with the majority reporting education beyond high school (84\%); and more than half (59\%) were employed at the time of the study, and roughly similar numbers of mothers reported the use of childcare $(60 \%)$. The most frequently reported household incomes were $\$ 25 \mathrm{~K}$ to $50 \mathrm{~K}(30 \%)$ and $50 \mathrm{~K}$ to $100 \mathrm{~K}(35 \%)$. Most mothers were married or living with a partner (83\%). On average, mothers were overweight with a mean BMI of $29 \pm 7 \mathrm{~kg} / \mathrm{m}^{2}$. On average, mothers had $2 \pm 1$ children living in the household. Just under half (48\%) were first time mothers. Slightly more than half of participating infants and toddlers were female (55\%). Ninety-four percent of the infants and $84 \%$ of the toddlers were ever breastfed, with $73 \%$ of mothers reporting breastfeeding for $\geq 3$ months. At the time of the study, $25 \%$ of mothers reported current breastfeeding. Infants/toddlers were growing normally, as indicated by mean weight-forlength z-scores of $0.06 \pm 0.78$ and $-0.13 \pm 0.99$ for infants and toddlers, respectively. Few children were underweight $\left(8 / 157\right.$ were $<5^{\text {th }}$ percentile weight-for-length) or obese $(5 / 157$ were $\geq 95^{\text {th }}$ percentile weight-for-length).

Of 157 participants in the larger study, 13 mothers reported having degrees in nutrition and/or psychology and were excluded from the feeding observation. Of the 144 dyads from which feeding data were obtained, $51 \%$ of coded data were taken from the $1^{\text {st }}$ feed recorded during the two-hour observation, $36 \%$ were $2^{\text {nd }}$ feeds, and the remainder was $3^{\text {rd }}$ or $4^{\text {th }}$ feeds (13\%). Approximately $6 \%$ of recorded feeds involved only breastfeeding, $9 \%$ involved only bottle-feeding, $22 \%$ involved only solid foods, and $63 \%$ involved mixed feeds of solids and liquids (e.g. breastmilk, formula, cow's milk, juice, water). Approximately $46 \%$ of children were observed to self-feed; 25 infants and 41 toddlers feed themselves independently or with minimal assistance from mothers. Caregiver responsiveness to hunger was not coded in 2 cases and responsiveness to fullness in 1 case due to poor recording quality.

\section{RCFCS Inter-rater Reliability}

As shown in Table 2, inter-rater reliability estimates for all RCFCS child variables based on ICC were excellent (ICC>0.80), with the exception of Relaxed Physical Disposition which was acceptable but fair (ICC $=0.60$ ). Inter-rater agreement for all RCFCS maternal variables was also excellent, with the exception of Relaxed Physical Disposition which was acceptable but fair (ICC $=0.51$ ). Reliability for coding the Strength of Child Late Hunger Cues as well as Maternal Negative Expressiveness toward the child during feeding, a component of General Responsiveness During Feeding, could not be estimated due to a low observed frequency of occurrence. 


\section{RCFCS General and Feeding Cue Responsiveness}

As shown in Table 3, Maternal and child General Responsiveness During Feeding were positively associated $(\mathrm{r}=0.54, \mathrm{p}<0.0001)$. As shown in Table $4,70 \%$ of mothers who were observed to be generally responsive to the child during feeding, based on visual attentiveness, expressiveness, and physical disposition, had children who showed similarly high responsiveness to their mothers. Similarly, $76 \%$ of unresponsive mothers had unresponsive infants or toddlers.

Mothers who were generally more responsive to the child during feeding also showed greater responsiveness to child feeding cues (mean of responsiveness to hunger, receptiveness to being fed, and fullness); this appeared to be primarily driven by maternal responsiveness to hunger cues (Table $3 ; \mathrm{r}=0.27, \mathrm{p}<0.01$ ). As shown in the Figure, mothers showed greater responsiveness to child hunger cues than to fullness cues $(\mathrm{p}<0.001)$; while $75 \%$ of mothers were observed to be responsive or highly responsive to child hunger cues, less than half (45\%) were observed to be similarly responsive to fullness cues. Reflecting the latency based definition of responsiveness to cues, mothers who showed greater responsiveness to child feeding cues tended to have children who were rated as displaying a lower strength of feeding cues $(\mathrm{r}=-0.49, \mathrm{p}<0.001)$. In turn, children who were also observed to display a lower strength of feeding cues, were more generally responsive to their mothers during feeding $(\mathrm{r}=-0.30, \mathrm{p}<0.001)$.

\section{RCFCS Criterion Validity}

As shown in Table 5, children who were observed to be more generally responsive to their mothers during feeding had mothers who tended to be older and report higher incomes. As shown in Tables 5 and 6, higher levels of general maternal responsiveness were seen among mothers who reported higher education, higher income, and fewer children in the household. Greater maternal responsiveness to hunger cues was seen among mothers of older children (toddlers vs. infants). Higher levels of maternal responsiveness to child fullness cues were seen among mothers who reported being married or living with a partner, having greater education and income, longer breastfeeding durations, who had lower BMIs, and whose children were observed to self-feed. Neither general responsiveness nor responsiveness to feeding cues was associated with child weight-for-length z-scores.

\section{Discussion}

While obesity prevention efforts are increasingly targeting children at early stages of development, the evidence base around child feeding remains weak. Recommendations for establishing healthy feeding relationships during the first two years of life remain largely based on expert opinion (Pac et al., 2004). The RCFCS was developed to create a theoretically-based, clinically-grounded observational measure of child feeding interactions relevant to obesity research during infancy and toddlerhood. The RCFCS behaviorally characterizes responsive feeding interactions based on observed child feeding cues and caregiver responsiveness to these cues during feeding as well as its initiation and termination. The evidence of inter-rater reliability and criterion validity presented in this report suggest that the initial psychometrics of the RCFCS are promising. 
The results revealed a high inter-rater agreement for most items, suggesting that coders can be trained to consistently detect the presence or absence of child feeding cues as well as rate dimensions of feeding responsiveness during infancy and toddlerhood. That generally high levels of agreement were obtained in a sample with roughly equal numbers of White, Black, and Hispanic caregivers suggests the consistent application of codes in a culturally-diverse sample. Inter-rater agreement for rating the physical disposition of the mother and child during feeding suggests that the operational definition of Relaxed Physical Disposition based on posture and movement was overly subjective and requires revision. While the data indicate that responsiveness at a feed may be rated similarly by independent raters, additional research is needed to determine the degree to which ratings at a single feed can be generalized. That feeding interactions may vary appreciably from feed to feed highlights the need for additional research to evaluate the test re-test reliability of the RCFCS dimensions both across meals and days.

The results also revealed a number of interesting substantive findings that provide initial evidence of validity. Mothers were observed to show greater responsiveness to child hunger cues than to fullness cues. The evolution of human biology has put into place complex and redundant pathways to fiercely defend body weight and protect against hunger (Zheng, Lenard, Shin, \& Berthoud, 2009). Our findings that mothers have greater sensitivity to child cues related to hunger than to satiation, may in part reflect a universal parental goal of children's survival and health (LeVine, 1988). Interestingly, mothers tended to be more responsive to the hunger and fullness cues of self-feeding children than younger children who were still primarily fed by the caregiver. These findings make sense in light of the increasing capacity of infants to communicate over the first year (Feldman, 2007; Givens, 1978; Hodges et al., 2008), which might not only increase the specificity of the child's cues but also the accuracy of the caregiver's interpretation.

Maternal responsiveness to child feeding cues reflected higher levels of general responsiveness during feeding. In turn, the general responsiveness of mother and child during feeding appeared reciprocal. The child's visual attentiveness and expressiveness during the feed reflected the mothers' engagement. This finding is consistent with research showing an influence of maternal responsiveness and sensitivity on the development of attentional processes in infancy and toddlerhood (Tamis-LeMonda \& Bornstein, 1989). Taken together, the results suggest that the general engagement of the caregiver with the child during feeding is related to but distinct from the caregiver's response to child feeding cues. While cross-sectional, the findings are consistent with the notion that the general sensitivity and responsiveness of the caregiver to the child may facilitate an ability to attend and appropriately respond to children's feeding cues.

Maternal responsiveness was correlated with a number of child and maternal characteristics. Of particular interest, mothers who reported longer breastfeeding durations were observed to show greater responsiveness to child fullness cues than other mothers. The dose-dependent protective effect of breastfeeding on the child obesity is thought to be partly explained by behavioral differences between breast and bottle feeding (Li, Fein, \& Grummer-Strawn, 2010). Whether and how the experience of breastfeeding shapes subsequent feeding beliefs and behaviors of the mothers remains unclear. It has been suggested that the infant-centered 
nature of breastfeeding supports healthy self-regulation of energy intake in infancy (Li et al., 2010; Wright, 1988; Wright, Fawcett, \& Crow, 1980) and toddlerhood (Brown \& Lee, 2012). Longer breastfeeding duration has been associated with lower subsequent levels of control in infant feeding (Blissett \& Farrow, 2007; Taveras et al., 2006; Taveras et al., 2004), whereas higher control in infant feeding is associated with a shorter duration of breastfeeding (Brown, Raynor, \& Lee, 2011). Recent findings suggest that breastfeeding of at least 6 weeks duration is needed in order to see positive effects on subsequent selfregulation of energy intake (Brown \& Lee, 2012). Taken together with the present findings, the available evidence suggests that mothers who engage in breastfeeding for longer durations may be more responsive to infant feeding cues.

In this study, mothers who were more generally responsive during feeding and those who showed greater responsiveness to feeding cues tended to have higher incomes and education levels. It is possible that more highly educated mothers have a greater understanding of child development, which may in turn be associated with key aspects of responsiveness: recognition and accurate interpretation of child cues. Given the bivariate, correlational nature of the findings, further investigation is needed to evaluate the unique contributions of maternal education and income to responsive feeding as well as their distinction from other potentially contributing influences such as breastfeeding duration.

Finally, maternal BMI was unrelated to observed responsiveness to child hunger cues, but was negatively associated with responsiveness to fullness cues. One interpretation of this finding is that overweight mothers may be less responsive to their own internal satiety cues (Benelam, 2009; Schachter, 1971) and increased awareness and responsiveness to one's own satiety cues facilitates the same in relation to one's child. Studies of child feeding styles and practices among older children, however, have produced inconsistent findings in efforts to identify an "obese" maternal feeding style (McPhie et al., 2011; Wardle et al., 2002).

However, it is important to note that the aforementioned research has focused on broader feeding constructs (e.g. pressure to eat, restriction) in which responsiveness to the child's cues and appetite is implicit but not specifically measured. Another potential explanation of the present finding is that the feeding cues of children with heavier mothers may be more difficult to interpret than those of other children. These interpretations merit further inquiry and provide potential targets for intervention.

A number of strengths and limitations merit discussion. First, while the RCFCS was developed with the assessment of obesogenic interactions in mind, its focus on feeding behaviors and caregiver responses to them in addition to elements of general responsiveness lends itself to use in other areas of feeding research, such as failure-to-thrive. In regard to limitations, the cross-sectional nature of our findings does not permit causal inferences. Longitudinal data are needed to better assess changes in patterns of interaction across time and development as well as their relevance for obesity risk. The sample was ethnicallydiverse, but mothers were relatively well-educated and breastfed longer than the US population norms (Centers for Disease Control and Prevention, 2011). In addition, that most of the infants and toddlers studied were of healthy weight-for-length (less than 5\% of the sample was obese) limits our ability to evaluate associations between responsiveness and obesity in this sample. A sample with a greater number of overweight/obese children is 
needed to evaluate the relationship, as well as to address the interesting question of whether such effects intensify with age and other potential moderators. Another limitation is the experimental setting. Feeding observations were video-recorded in a private room in a laboratory setting. While dyads were given time to acclimate to the room, it is possible that maternal and child reactivity to the novelty of the setting and/or maternal reactivity to being remotely video-recorded may have altered interactive behaviors. Because the coding scheme and procedures are not specific to a laboratory setting, future studies using the RCFCS to evaluate dyadic feeding responsiveness could be conducted in more naturalistic settings. Understanding the sensitivity of the RCFCS to detect changes in caregiver responsiveness with various home- and/or clinic-based feeding interventions will be important for establishing the clinical utility of the RCFCS. Finally, evidence of convergent and predictive validity including the correspondence of the RCFCS to self-report measures of parental and child feeding behaviors is needed.

In conclusion, the RCFCS is a reliable observational measure of responsive feeding for children $<2$ years of age that is relevant to obesity in early development. Given inclusion of a broad range of feeding cues during early development, use of the RCFCS can provide greater insight into the development and diversity of feeding cues from birth through toddlerhood. With calls for increasing attention to child feeding cues as a means of obesity prevention (Committee on Obesity Prevention Policies for Young Children, 2011) the RCFCS should also prove to be a useful tool in identifying cues clinicians can use to guide parents and other caregivers in preventing obesity in young children. The ability to assess responsiveness as an interactive dynamic construct over a feeding has implications for tailoring potential interventions to behavior occurring at different points during the feed (i.e. the response to child hunger, receptiveness to being fed, and fullness). Further, the tool facilitates sequential coding (Bakeman \& Quera, 2011), which should enable identification of salient behavioral patterns within and across different points in development. Finally, should the RCFCS prove sensitive to change, it may serve as an indicator of the efficacy of interventions to enhance feeding responsiveness and alter the risk trajectory for obesity.

\section{Acknowledgments}

The authors would like to acknowledge Wendy Tovar, Felicita Aguilar, and Monica Lopez for their efforts in coding the data, Yan Liu for assistance with the calculation of interrater reliabilities, and the staff of the USDA/ARS Children's Nutrition Research Center's Metabolic Research Unit for assistance with collecting the data.

Funding This work was supported by the National Institute of Health (Grant Number DK 56350) (EAH); US Department of Agriculture National Research Institute (Grant Number 2005-55215-616726) (SLJ); US Department of Agriculture CRIS Funds to the USDA/ARS Children's Nutrition Research Center Houston TX (JOF; NFB); National Institute of Health (Grant Number K01 DK 61319) (JOF); and Nestle Infant Nutrition (NFB, JOF).

\section{References}

Agras WS, Hammer LD, Huffman LC, Mascola A, Bryson SW, Danaher C. Improving healthy eating in families with a toddler at risk for overweight: a cluster randomized controlled trial. Journal of Developmental \& Behavioral Pediatrics. 2012; 333(7):529-534. doi: 10.1097/DBP. 0b013e3182618e1f. [PubMed: 22947882]

Ainsworth, MDS.; Bell, SM. Some contemporary patterns of mother-infant interaction in the feeding situation Stimulation in early infancy. Academic Press; New York: 1969. 
Ainsworth, MDS.; Bell, SM.; Stayton, DJ. Infant-mother attachement and social development: "Socialization" as a product of reciprocal responsiveness to signals. In: Richards, MPM., editor. The intergration of a child into a social world. Cambridge University Press; London: 1974. p. 99-135.

Ainsworth, MS. Maternal sensitivity scales. Johns Hopkins University; Baltimore, MD: 1969. manuscript

Bakeman, R.; Quera, V. Sequential analysis and observational methods for the behavioral sciences. Cambridge University Press; Cambridge, UK: 2011.

Beebe, B.; Stern, D. Engagement-disengagement and early object experience. In: Freedman, M.; Grenel, S., editors. Communicative structures and psychic structures. Plenum Press; New York: 1977. p. 33-55

Benelam B. Satiety and the anorexia of ageing. British Journal of Community Nursing. 2009; 14(8): 332-335. [PubMed: 19684553]

Birch LL, Fisher JO, Castro CN, Grimm-Thomas K, Sawyer R, Johnson SL. Confirmatory factor analysis of the Child Feeding Questionnaire: a measure of parental attitudes, beliefs and practices about child feeding and obesity proneness. Appetite. 2001; 36(3):201-210. [PubMed: 11358344]

Black MM, Aboud FE. Responsive feeding is embedded in a theoretical framework of responsive parenting. Journal of Nutrition. 2011; 141(3):490-494. doi: jn.110.129973. [PubMed: 21270366]

Blacker, D. Psychiatric Rating Scales. In: Sadock, BJ.; Sadock, V., editors. Textbook of Psychiatry. 8th Ed. Lippincott Williams \& Wilkins; Philadelphia: 2005. p. 929-955.

Blissett J, Farrow C. Predictors of maternal control of feeding at 1 and 2 years of age. International Journal of Obesity. 2007; 31(10):1520-1526. doi: 10.1038/sj.ijo.0803661. [PubMed: 17579636]

Blundell J, de Graaf C, Hulshof T, Jebb S, Livingstone B, Lluch A. Appetite control: methodological aspects of the evaluation of foods. Obesity Reviews. 2010; 11(3):251-270. doi: 10.1111/j. 1467-789X.2010.00714.x. [PubMed: 20122136]

Bornstein, MH. Maternal responsivenes: characteristics and consequences. Jossey-Bass; San Francisco: 1989.

Bowlby, J. Attachment and loss. Vol. Vol. 1. Basic Books; New York: 1969. Vol.Attachment

Brisbois TD, Farmer AP, McCargar LJ. Early markers of adult obesity: a review. Obesity Reviews. 2012; 13(4):347-367. doi: 10.1111/j.1467-789X.2011.00965.x. [PubMed: 22171945]

Brown A, Lee M. Maternal child-feeding style during the weaning period: association with infant weight and maternal eating style. Eating Behaviors. 2011a; 12(2):108-111. doi: 10.1016/j.eatbeh. 2011.01.002. [PubMed: 21385639]

Brown A, Lee M. Maternal control of child feeding during the weaning period: differences between mothers following a baby-led or standard weaning approach. Maternal \& Child Health Journal. 2011b; 15(8):1265-1271. doi: 10.1007/s10995-010-0678-4. [PubMed: 20830511]

Brown A, Lee M. Breastfeeding during the first year promotes satiety responsiveness in children aged 18-24 months. Pediatric Obesity. 2012; 7(5):382-390. doi: 10.1111/j.2047-6310.2012.00071.x. [PubMed: 22911888]

Brown A, Raynor P, Lee M. Maternal control of child-feeding during breast and formula feeding in the first 6 months post-partum. Journal of Human Nutrition \& Dietetics. 2011; 24(2):177-186. doi: 10.1111/j.1365-277X.2010.01145.x. [PubMed: 21332836]

Bruch H. Developmental considerations of anorexia nervosa and obesity. Canadian Journal of Psychiatry. 1981; 26:212-217.

Centers for Disease Control and Prevention. Breastfeeding among US children born 1999-2007, CDC national immunization survey. provisional breastfeeding rates by socio-demographic factors, among children born in 2007. 2011. Retrieved fromhttp://www.cdc.gov/breastfeeding/data/ nis_data/

Chatoor I, Getson P, Menvielle E, Brasseaux C, O’Donnell R, Rivera Y. A feeding scale for research and clinical practice to assess mother-infant interactions in the first three years of life. Infant Mental Health. 1997; 18(1):76-91.

Clark R. The parent-child early relational assessment: A factorial validity study. Educational and Psychological Measurement. 1999; 59(5):821-846.

Committee on Obesity Prevention Policies for Young Children. Early Childhood Obesity Prevention Policies. Institute of Medicine., editor. The National Academies Press; Washington, DC: 2011. 
Costanzo PR, Woody EZ. Domain-specific parenting styles and their impact on the child's development of a particular deviance: the example of obesity proneness. Journal of Social and Clinical Psychology. 1985; 4:425-445.

Crow RA. An ethological study of the development of infant feeding. Journal of Advanced Nursing. 1977; 2:99-109. [PubMed: 122767]

DiSantis KI, Hodges EA, Johnson SL, Fisher JO. The role of responsive feeding in overweight during infancy and toddlerhood: a systematic review. International Journal of Obesity. 2011; 35(4):480492. doi:10.1038/ijo.2011.3. [PubMed: 21427696]

Engle PL, Bentley ME, Pelto G. The role of care in nutrition programmes:current research a research agenda. Proceedings of the Nutrition Society. 2000; 59:25-35. [PubMed: 10828171]

Farrow C, Blissett J. Does maternal control during feeding moderate early infant weight gain? Pediatrics. 2006; 118(2):e293-e298. [PubMed: 16882774]

Farrow CV, Blissett J. Controlling feeding practices: cause or consequence of early child weight? Pediatrics. 2008; 121(1):e164-169. doi: 10.1542/peds.2006-3437. [PubMed: 18166535]

Feldman R. Parent-infant synchrony and the construction of shared timing; physiological precursors, developmental outcomes, and risk conditions. Journal of Child Psychology \& Psychiatry. 2007; 48(3-4):329-354. doi: 10.1111/j.1469-7610.2006.01701.x. [PubMed: 17355401]

Fisher JO, Butte NF, Mendoza PM, Wilson TA, Hodges EA, Reidy KC. Overestimation of infant and toddler energy intake by 24-h recall compared with weighed food records. American Journal of Clinical Nutrition. 2008; 88(2):407-415. doi: 88/2/407 [pii]. [PubMed: 18689377]

Fleiss JL. Measuring nominal scale agreement among many raters. Psychological Bulletin. 1971; 76:378-382.

Gesell, A.; Ilg, FL. Feeding behavior of infants: A pediatric approach to the mental hygiene of early life. J.B. Lippincott Company; Philadelphia, PA: 1937.

Givens DB. Social expressivity during the first year of life. Sign Language Studies. 1978; 20:251-274.

Harrington JW, Nguyen VQ, Paulson JF, Garland R, Pasquinelli L, Lewis D. Identifying the "tipping point” age for overweight pediatric patients. Clinical Pediatrics. 2010; 49(7):638-643. doi: 10.1177/0009922809359418. [PubMed: 20150210]

Hodges EA, Hughes SO, Hopkinson J, Fisher JO. Maternal decisions about the initiation and termination of infant feeding. Appetite. 2008; 50(2-3):333-339. doi: 10.1016/j.appet.2007.08.010. [PubMed: 17977617]

Hughes SO, Power TG, Orlet Fisher J, Mueller S, Nicklas TA. Revisiting a neglected construct: parenting styles in a child-feeding context. Appetite. 2005; 44:83-92. [PubMed: 15604035]

Hurley KM, Cross MB, Hughes SO. A systematic review of responsive feeding and child obesity in high-income countries. Journal of Nutrition. 2011; 141(3):495-501. doi: 10.3945/jn.110.130047. [PubMed: 21270360]

Korner AF, Chuck B, Dontchos S. Organismic determinants of spontaneous oral behavior in neonates. Child Development. 1968; 39(4):1145-1157. [PubMed: 5704392]

Kuczmarski RJ, Ogden CL, Grummer-Strawn LM, Flegal KM, Guo SS, Wei R. CDC growth charts: United States. Advance Data. 2000; 314:1-27. [PubMed: 11183293]

Lamb, ME.; Easterbrooks, MA. Individual differences in parental sensitivity: Origins, components, and consequences. In: Lamb, ME.; Sherrod, LR., editors. Infant social cognition: Empirical and theoretical considerations. Erlbaum; Hillsdale, NJ: 1981. p. 127-153.

Landis JR, Koch GG. The measurement of observer agreement for categorical data. Biometrics. 1977; 33(1):159-174. [PubMed: 843571]

Lavelli M, Poli M. Early mother-infant interaction during breast-and bottle-feeding. Infant Behavior \& Development. 1998; 21(4):667-684.

LeVine, RA. Human parental care: universal goals, cultural strategies, individual behavior. In: Levine, RA.; Miller, PM.; West, MM., editors. Parental behavior in diverse societies. Jossey-Bass; San Francisco, CA: 1988. p. 3-12.

Lewis M, Worobey J. Mothers and toddlers lunch together. The relation between observed and reported behavior. Appetite. 2011; 56(3):732-736. doi: 10.1016/j.appet.2011.02.011. [PubMed: 21349305] 
Li R, Fein SB, Grummer-Strawn LM. Do infants fed from bottles lack self-regulation of milk intake compared with directly breastfed infants? Pediatrics. 2010; 125(6):e1386-1393. doi: 10.1542/peds. 2009-2549. [PubMed: 20457676]

Lindahl, KM. Methodological Issues in Family Observational Research. In: Kerig, PK.; Lindahl, KM., editors. Family Observational Coding Systems: Resources for Systemic Research. Lawrence Erlbaum Associates; Mahwah, NJ: 2001.

Lohman, TG.; Roche, AF.; Martorell, R. Anthropometric standardization reference manual. Human Kinetics Books; Champaign, IL: 1988.

McPhie S, Skouteris H, McCabe M, Ricciardelli LA, Milgrom J, Baur LA. Maternal correlates of preschool child eating behaviours and body mass index: a cross-sectional study. International Journal of Pediatric Obesity. 2011; 6(5-6):476-480. doi: 10.3109/17477166.2011.598937. [PubMed: 21780868]

Mentro AM, Steward DK, Garvin BJ. Infant feeding responsiveness: a conceptual analysis. Journal of Advanced Nursing. 2002; 37(2):208-216. doi: 10.1046/j.1365-2648.2002.02068.x. [PubMed: 11851789]

Morris SS, Rogers CS, Taper LJ. Care-giving behaviors in feeding 3-, 13-, and 23-month-old infants. Nutrition and Behavior. 1983; 1:147-156.

Musher-Eizenman D, Holub S. Comprehensive Feeding Practices Questionnaire: validation of a new measure of parental feeding practices. Journal of Pediatric Psychology. 2007; 32(8):960-972. doi: 10.1093/jpepsy/jsm037. [PubMed: 17535817]

Ogden CL, Carroll MD, Kit BK, Flegal KM. Prevalence of obesity and trends in body mass index among US children and adolescents, 1999-2010. JAMA. 2012; 307(5):483-490. doi: 10.1001/ jama.2012.40. [PubMed: 22253364]

Pac S, McMahon K, Ripple M, Reidy K, Ziegler P, Myers E. Development of the Start Healthy Feeding Guidelines for Infants and Toddlers. Journal of the American Dietetic Association. 2004; 104(3):455-467. [PubMed: 14993871]

Paul IM, Bartok CJ, Downs DS, Stifter CA, Ventura AK, Birch LL. Opportunities for the primary prevention of obesity during infancy. Advances in Pediatrics. 2009; 56:107-133. doi: 10.1016/ j.yapd.2009.08.012. [PubMed: 19968945]

Sacco LM, Bentley ME, Carby-Shields K, Borja JB, Goldman BD. Assessment of infant feeding styles among low-income African-American mothers: comparing reported and observed behaviors. Appetite. 2007; 49(1):131-140. doi: 10.1016/j.appet.2007.01.004. [PubMed: 17336423]

Sameroff A, Chandler M. Transactional models in early social relations. Human Development. 1975; 18:65-79.

Schachter S. Some extraordinary facts about obese humans and rats. American Psychologist. 1971; 26(2):129-144. [PubMed: 5541215]

Shrout PE, Fleiss JL. Intraclass correlations: uses in assessing rater reliability. Psychological Bulletin. 1979; 86(2):420-428. [PubMed: 18839484]

Slaughter MH, Lohman TG. Relationship of body composition to somatotype. American Journal of Physical Anthropology. 1976; 44(2):237-244. doi: 10.1002/ajpa.1330440205. [PubMed: 1258983]

Sumner, G.; Spietz, A. NCAST caregiver/parent-child interaction teaching manual. NCAST Publications, University of Washington, School of Nursing; Seattle: 1994.

Tamis-LeMonda CS, Bornstein MH. Habituation and maternal encouragement of attention in infancy as predictors of toddler language, play, and representational competence. Child Development. 1989; 60(3):738-751. [PubMed: 2737021]

Taveras EM, Rifas-Shiman SL, Scanlon KS, Grummer-Strawn LM, Sherry B, Gillman MW. To what extent is the protective effect of breastfeeding on future overweight explained by decreased maternal feeding restriction? Pediatrics. 2006; 118(6):2341-2348. doi: 10.1542/peds.2006-1814. [PubMed: 17142517]

Taveras EM, Scanlon KS, Birch L, Rifas-Shiman SL, Rich-Edwards JW, Gillman MW. Association of breastfeeding with maternal control of infant feeding at age 1 year. Pedatrics. 2004; 114:e577-583.

Townsend E, Pitchford NJ. Baby knows best? The impact of weaning style on food preferences and body mass index in early childhood in a case-controlled sample. BMJ Open. 2012; 2(1):e000298. doi: 10.1136/bmjopen-2011-000298. 
Ventura AK, Birch LL. Does parenting affect children's eating and weight status? International Journal of Behavioral Nutrition \& Physical Activity. 2008; 5:15. doi: 10.1186/1479-5868-5-15. [PubMed: 18346282]

Wardle J, Sanderson S, Guthrie CA, Rapoport L, Plomin R. Parental feeding style and the intergenerational transmission of obesity risk. Obesity. 2002; 10(6):453-462. doi: 10.1038/oby. 2002.63.

Wolke, D.; Sumner, M.; McDermott, Y.; Skuse, D. The feeding interaction scale. University of Hertfordshire; Hatfield, Hetfordshire: 1987. unpublished work

Wright P. Development of feeding behavior in early infancy: implications for obesity. Health Bulletin. 1981; 39(3):197-205. [PubMed: 7251354]

Wright, P. Hunger, satiety, and feeding behaviour in early infancy. In: Boakes, RA.; Popplewell, DA.; Burton, MJ., editors. Eating Habits: Food, Physiology and Learned Behaviour. John Wiley \& Sons; Chichester: 1987.

Wright P. Learning experiences in feeding behaviour during infancy. Journal of Psychosomatic Research. 1988; 32(6):613-619. [PubMed: 3065486]

Wright P, Fawcett J, Crow R. The development of differences in the feeding behaviour of bottle and breast fed human infants from birth to two months. Behavioural Processes. 1980; 5:1-20.

Zheng H, Lenard NR, Shin AC, Berthoud HR. Appetite control and energy balance regulation in the modern world: reward-driven brain overrides repletion signals. International Journal of Obesity. 2009; 33(Suppl 2):S8-13. doi: 10.1038/ijo.2009.65. [PubMed: 19528982] 


\section{Highlights}

- The RCFCS reliably assesses feeding interactions for children aged 7-24 months.

- Mother and child general responsiveness during feeding appeared reciprocal.

- General and feeding cue responsiveness were distinct but correlated constructs.

- Mothers were observed to be more responsive to child hunger than fullness cues. 


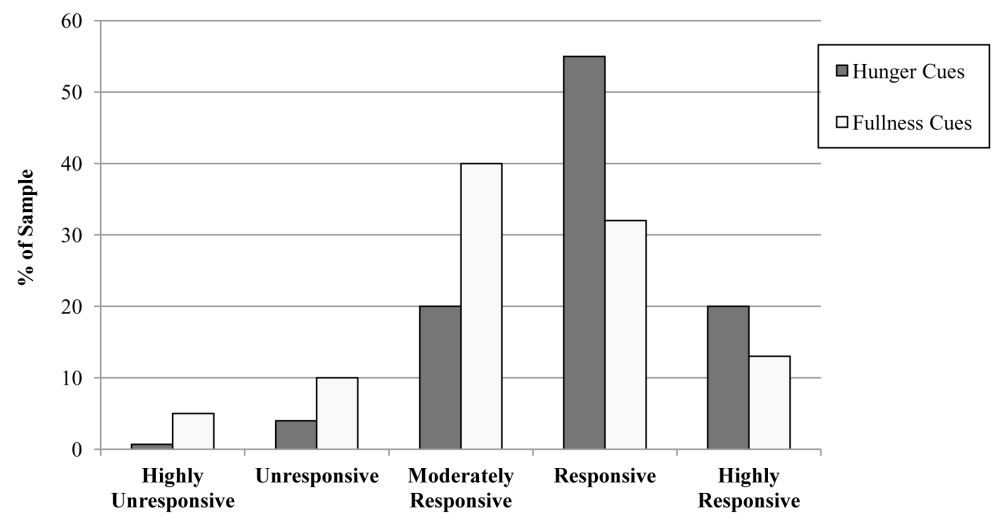

Figure. Frequency Distribution of Maternal Responsiveness to Child Hunger ${ }^{\mathrm{a}}$ and Fullness Cues (n=144) ${ }^{a}$ Mean of Maternal Responsiveness to Child Hunger Cues and Maternal Responsiveness to the Child's Receptiveness to Being Fed. Mothers were observed to be more responsive to child hunger cues than fullness cues (paired t-test; $\mathrm{p}<0.0001$ ). 


\section{Table 1}

\section{Responsiveness to Child Feeding Cues Scale Variable Definitions and Scoring ${ }^{a}$}

\begin{tabular}{|c|c|}
\hline Variable & Scoring \\
\hline \multicolumn{2}{|l|}{ General Responsiveness During Feeding $b$} \\
\hline Visual Attentiveness: Looking at or in the direction of the caregiver/child & $\begin{array}{l}5=\text { Very } \\
4=\text { Fairly }\end{array}$ \\
\hline $\begin{array}{l}\text { Positive Expressiveness: Vocalizations (e.g. babbling, talking) and /or } \\
\text { non-verbal expressions (e.g. clapping, patting) of an affirmative, } \\
\text { affectionate, and/or delighted tone or nature }\end{array}$ & $\begin{array}{l}3=\text { Somewhat } \\
2=\text { Not Very } \\
1=\text { Not at all }\end{array}$ \\
\hline
\end{tabular}

Negative Expressiveness (reverse-coded): Vocalizations (e.g. fussing) and /or non-verbal expressions (e.g. hitting, kicking) of a negative, distressed, punitive, and/or forceful tone or nature

Relaxed Physical Disposition: Combination of relaxed posture, quiet movements during feeding (e.g. molding to caregiver's body)

Child Feeding Cues

Hunger (4 early, 13 active, 3 late cues): Coded from the beginning of the observation until 1 minute following the first bite

Presence (and frequency) vs. Absence

Fullness ( 9 early, 15 active, 4 late cues): Coded from the beginning of food preparation until food/infant was removed from feeding location

\section{Caregiver Responsiveness to Child Feeding Cues}

Hunger Cues: The latency of the caregiver's feeding response to child hunger cues. Rated based on the type (e.g. early, active, late) of hunger cues observed from the beginning of the observation until food preparation or placing child in feeding position

Receptiveness to Being Fed: The response of the caregiver to child hunger and fullness cues observed from the beginning of food preparation or placing child in feeding position until 1 minute following the first food to mouth contact.

Fullness Cues: The latency of the caregiver's feeding response to child fullness cues. Rated based on the type (e.g. early, active, late) of fullness cues observed 1 minute after the first food to mouth contact up to the time at which the food or child was removed from feeding location-whichever came first.

${ }^{a}$ The full instrument including coding sheets and definitions may be obtained by request to the first (EAH) or corresponding (JOF) author

${ }^{b}$ Scored separately for mother and child
$5=$ Highly

4=Responsive

$3=$ Somewhat

$2=$ Not very

$1=$ Not at all 


\section{Table 2}

Inter-rater agreement for all RCFCS variables ${ }^{a}$

\begin{tabular}{lc}
\hline Variable & ICC \\
\hline Child General Responsiveness to Mother & \\
During Feeding & \\
Visual Attentiveness & 0.86 \\
Positive Expressiveness & 0.99 \\
Negative Expressiveness & 0.97 \\
Physical Disposition & 0.60 \\
Strength of Hunger Cues & \\
Early/Subtle & 0.99 \\
Positive Active & 1 \\
Negative Active & 1 \\
Late & $\mathrm{NE}$ \\
Strength of Fullness Cues & \\
Early/Subtle & 1 \\
Positive Active & 0.99 \\
Negative Active & 1 \\
Late & $1 b$ \\
Caregiver General Responsiveness to & \\
Child During Feeding & \\
Visual Attentiveness & 0.92 \\
Positive Expressiveness & 0.97 \\
Negative Expressiveness & $\mathrm{NE}$ \\
Physical Disposition & 0.94 \\
Caregiver Responsiveness to Child & \\
Hunger Cues $c$ & \\
Caregiver Responsiveness to Child & \\
Fullness Cues & \\
\hline
\end{tabular}

Note: ICC=Intra-class correlation coefficient (absolute agreement); NE=not estimated due to zero variability

$a_{\mathrm{n}=144}$ mothers and children aged 7-24 mo, scored by 3 raters

${ }^{b}$ Cohen's Kappa Coefficient

${ }^{c}$ Mean of Maternal Responsiveness to Child Hunger Cues and Maternal Responsiveness to the Child's Receptiveness to Being Fed 


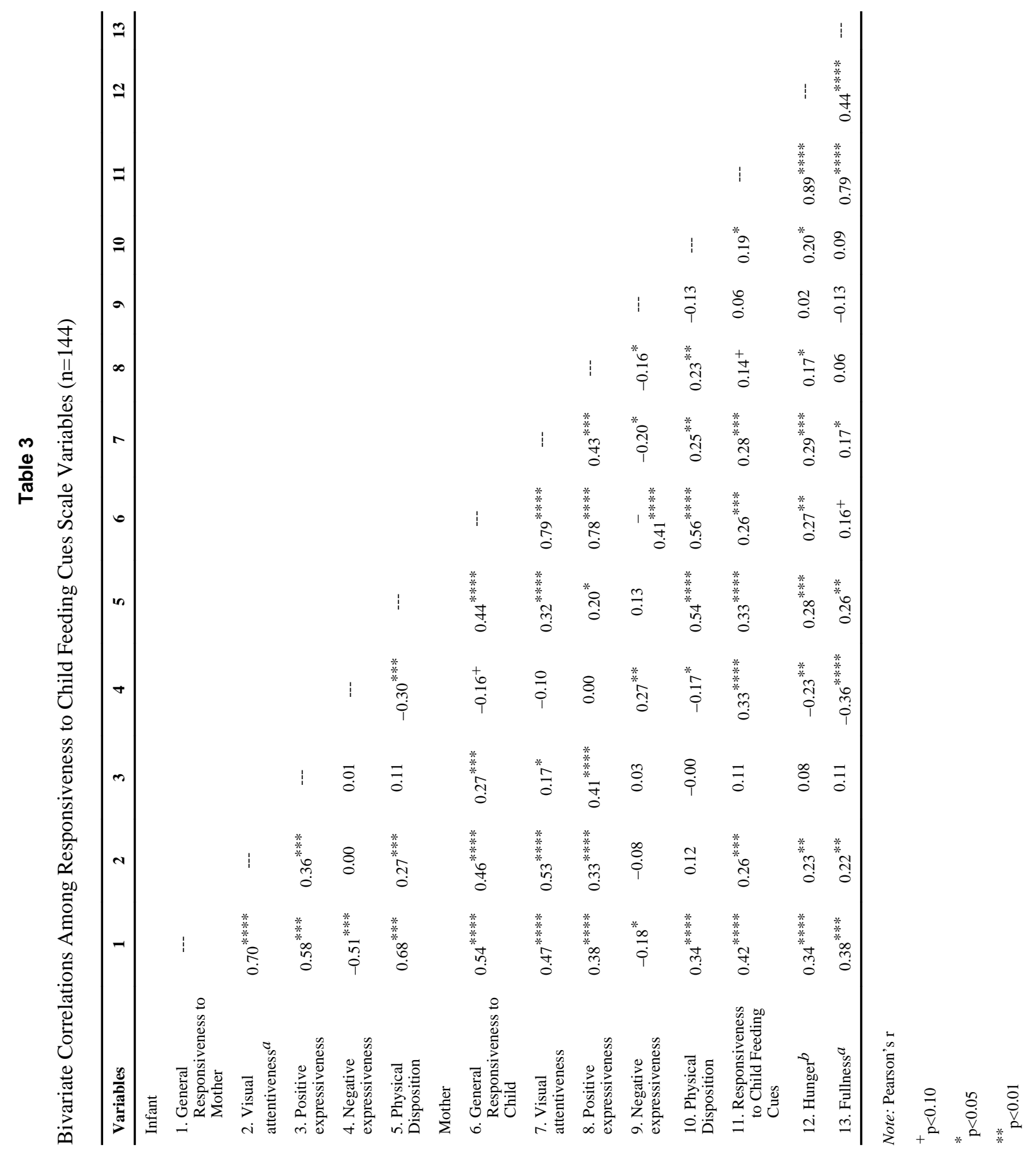




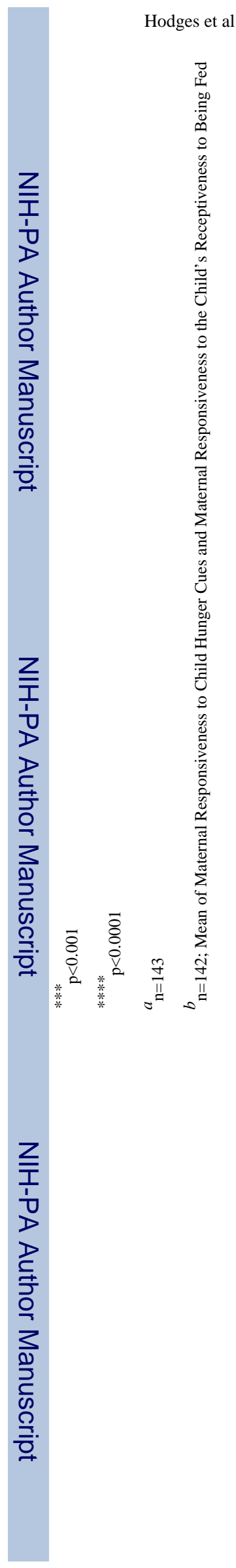

Page 23

Appetite. Author manuscript; available in PMC 2014 June 01. 
Table 4

Correspondence of Mother and Child General Feeding Responsiveness ${ }^{a, b}$

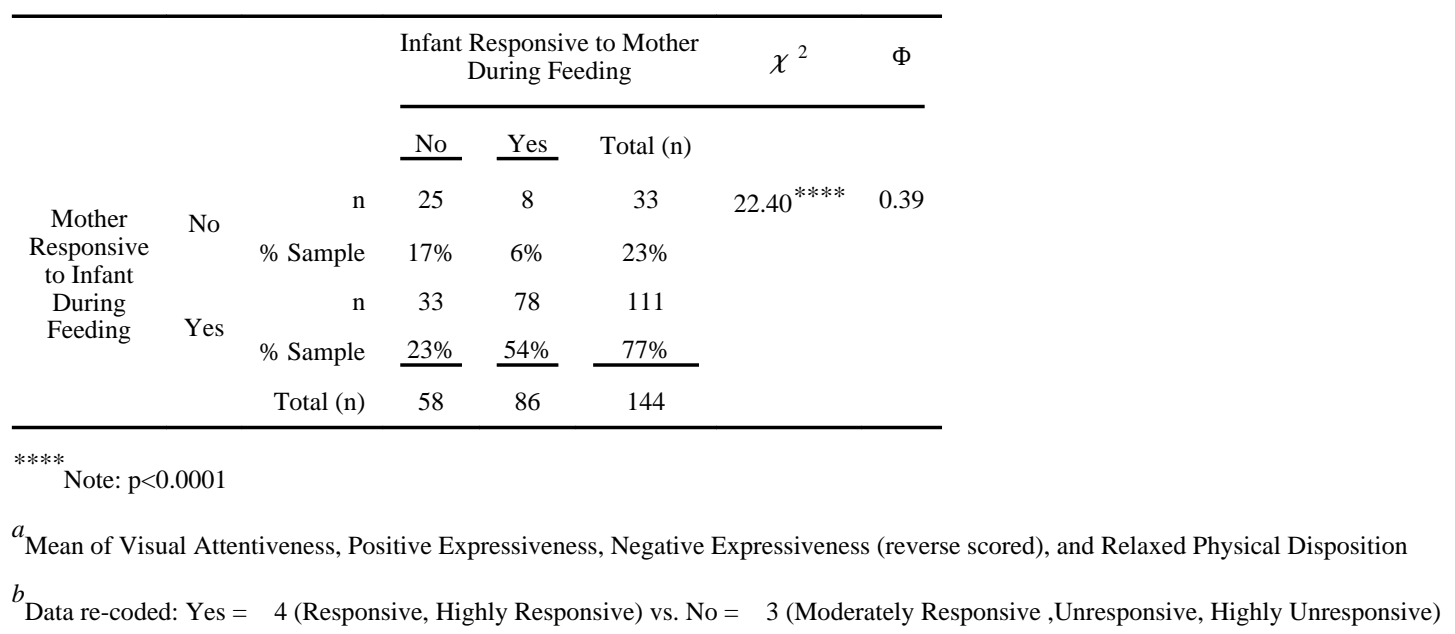


Table 5

Correlations between RFCS responsiveness and selected demographics

\begin{tabular}{lcccc}
\hline & $\begin{array}{c}\text { Child General } \\
\text { Responsiveness } \\
\text { to Mother } \\
\text { During } \\
\text { Feeding }\end{array}$ & $\begin{array}{c}\text { Maternal General } \\
\text { Responsiveness } \\
\text { to Child } \\
\text { During Feeding } \boldsymbol{a}\end{array}$ & $\begin{array}{c}\text { Maternal } \\
\text { Responsiveness } \\
\text { to Child } \\
\text { Hunger Cues } \boldsymbol{b}\end{array}$ & $\begin{array}{c}\text { Maternal } \\
\text { Responsiveness } \\
\text { to Child } \\
\text { Fullness Cues }\end{array}$ \\
\hline Maternal & $0.18^{*}$ & $0.15^{+}$ & 0.10 & 0.02 \\
Age (y) & -0.06 & 0.00 & -0.01 & $-0.18^{*}$ \\
Body Mass Index (kg/m $\left.{ }^{2}\right)$ & $0.24^{* *}$ & $0.16^{*}$ & 0.08 & -0.00 \\
Household Income & 0.07 & $-0.17^{*}$ & -0.07 & -0.10 \\
Children in Household & $0.14^{+}$ & $0.14^{+}$ & 0.07 & $0.19^{*}$ \\
Breastfeeding Duration & -0.11 & 0.03 & -0.07 & -0.06 \\
Child & & & & \\
Weight-for-length Z-score & & & & \\
\hline
\end{tabular}

${ }^{+}$Notes: Associations tested using Pearson's rank order correlations; $\mathrm{p}<0.10$

p $<0.05$

** $\mathrm{p}<0.01$

*** $\mathrm{p}<0.001$

${ }^{a}$ On a 5 point scale; Mean of Visual Attentiveness, Positive Expressiveness, Negative Expressiveness (reverse scored), and Relaxed Physical Disposition; $\mathrm{n}=144$

${ }^{b}$ On a 5 point scale; Mean of Maternal Responsiveness to Child Hunger Cues and Maternal Responsiveness to the Child's Receptiveness to Being Fed; $\mathrm{n}=142$

$c_{\mathrm{n}=143}$ 
Table 6

Comparing mean RFCS responsiveness across selected demographic characteristics

\begin{tabular}{|c|c|c|c|c|}
\hline & $\begin{array}{c}\text { Child General } \\
\text { Responsiveness to } \\
\text { Mother During Feeding } a\end{array}$ & $\begin{array}{c}\text { Maternal General } \\
\text { Responsiveness to } \\
\text { Child During Feeding } a\end{array}$ & $\begin{array}{c}\text { Maternal } \\
\text { Responsiveness to } \\
\text { Child Hunger Cues }{ }^{b}\end{array}$ & $\begin{array}{c}\text { Maternal } \\
\text { Responsiveness to } \\
\text { Child Fullness Cues }\end{array}$ \\
\hline \multicolumn{5}{|l|}{ Maternal } \\
\hline Ethnicity & $F(2,141)=0.57$ & $F(2,141)=2.51^{+}$ & $F(2,139)=1.51$ & $F(2,140)=2.96^{+}$ \\
\hline Black $(\mathrm{n}=49)$ & $3.19(0.67)$ & $3.48(0.68)$ & $4.01(0.78)$ & $3.14(1.12)$ \\
\hline Hispanic $(n=47)$ & $3.24(0.54)$ & $3.70(0.56)$ & $3.98(0.83)$ & $3.33(1.01)$ \\
\hline White $(\mathrm{n}=48)$ & $3.32(0.59)$ & $3.73(0.55)$ & $4.22(0.59)$ & $3.63(0.79)$ \\
\hline Education & $F(1,142)=4.75^{*}$ & $F(1,142)=4.99^{*}$ & $F(1,140)=2.46$ & $F(1,141)=4.90^{*}$ \\
\hline$\leq$ High School $(\mathrm{n}=24)$ & $3.01(0.64)$ & $3.39(0.60)$ & $3.85(0.73)$ & $2.96(1.08)$ \\
\hline$>$ High School $(\mathrm{n}=120)$ & $3.30(0.59)$ & $3.69(0.60)$ & $4.11(0.74)$ & $3.44(0.96)$ \\
\hline Marital Status & $F(1,142)=2.53$ & $F(1,142)=0.08$ & $F(1,140)=0.59$ & $F(1,141)=6.03^{*}$ \\
\hline Single $(\mathrm{n}=18)$ & $3.04(0.54)$ & $3.60(0.64)$ & $3.94(1.00)$ & $2.83(1.20)$ \\
\hline Married/Partner $(n=126)$ & $3.28(0.61)$ & $3.64(0.61)$ & $4.09(0.70)$ & $3.44(0.95)$ \\
\hline Employment & $F(1,142)=0.53$ & $F(1,142)=2.25$ & $F(1,140)=0.24$ & $F(1,141)=0.04$ \\
\hline Employed (n=84) & $3.28(0.62)$ & $3.70(0.65)$ & $4.10(0.72)$ & $3.35(1.06)$ \\
\hline Unemployed $(\mathrm{n}=60)$ & $3.20(0.58)$ & $3.55(0.54)$ & $4.03(0.79)$ & $3.38(0.90)$ \\
\hline \multicolumn{5}{|l|}{ Child } \\
\hline Age Group & $F(1,142)=1.48$ & $F(1,142)=0.01$ & $F(1,140)=4.34^{*}$ & $F(1,141)=1.77$ \\
\hline Infant $(\mathrm{n}=74)$ & $3.19(0.61)$ & $3.63(0.60)$ & $3.95(0.72)$ & $3.26(0.97)$ \\
\hline Toddler $(\mathrm{n}=70)$ & $3.31(0.59)$ & $3.64(0.62)$ & $4.20(0.75)$ & $3.48(1.02)$ \\
\hline Gender & $F(1,142)=0.00$ & $F(1,142)=0.67$ & $F(1,140)=0.04$ & $F(1,141)=1.00$ \\
\hline Male $(n=63)$ & $3.25(0.57)$ & $3.68(0.67)$ & $4.06(0.77)$ & $3.27(1.13)$ \\
\hline Female $(\mathrm{n}=81)$ & $3.25(0.63)$ & $3.60(0.56)$ & $4.08(0.73)$ & $3.44(0.87)$ \\
\hline Observed Feed Type & $F(1,142)=2.89^{*}$ & $F(1,142)=2.29^{+}$ & $F(1,140)=0.25$ & $F(1,141)=1.46$ \\
\hline Breast-fed $(n=8)$ & $3.28(0.54)$ & $3.81(0.56)$ & $4.14(0.48)$ & $3.75(0.89)$ \\
\hline Bottle-fed ( $\mathrm{n}=13)$ & $2.85(0.75)$ & $3.27(0.53)$ & $3.96(0.80)$ & $2.92(1.16)$ \\
\hline Solid $(\mathrm{n}=30)$ & $3.30(0.48)$ & $3.59(0.65)$ & $4.03(0.84)$ & $3.50(0.86)$ \\
\hline Mixed Feeding ( $\mathrm{n}=86$ ) & $3.34(0.59)$ & $3.70(0.58)$ & $4.12(0.69)$ & $3.34(1.00)$ \\
\hline Observed to Self-Feed & $F(1,142)=1.85$ & $F(1,142)=2.05$ & $F(1,140)=2.79^{+}$ & $F(1,141)=12.75^{* * *}$ \\
\hline No $(n=78)$ & $3.19(0.59)$ & $3.70(0.62)$ & $3.97(0.73)$ & $3.10(0.99)$ \\
\hline Yes $(n=66)$ & $3.33(0.61)$ & $3.56(0.59)$ & $4.18(0.75)$ & $3.67(0.92)$ \\
\hline \multicolumn{5}{|l|}{$* p<0.05$} \\
\hline \multicolumn{5}{|l|}{ ** $<<0.01$} \\
\hline \multicolumn{5}{|l|}{${ }^{* * *} \mathrm{p}<0.001$} \\
\hline
\end{tabular}


${ }^{b}$ On a 5 point scale; Mean of Maternal Responsiveness to Child Hunger Cues and Maternal Responsiveness to the Child's Receptiveness to Being Fed; $n=142$

$c_{\mathrm{n}=143}$

$d$ One-way ANOVA 